\title{
THE INFLUENCE OF BIOTIC AND ABIOTIC FACTORS ON BAT ACTIVITY IN NEGEV DESERT, ISRAEL
}

\author{
Aeshita Mukherjee ${ }^{1}$ and Carmi Korine
}

Department of Desert Research, Jacob Blaustein Institute, Sede Boqer, Israel.

${ }^{I}$ Address for correspondence: Gujarat Institute of Development Research, Nr. Gota Chokdi, Gota, Ahmedabad, Gujarat 380060, India.

Email: aeshitam@rediffmail.com

\begin{abstract}
The effect of biotic factors (vegetation cover and insect abundance) and abiotic factors (ambient temperatures, cloud cover and wind strength) on bat activity was studied during May 2001 in four different sized wadies around Sede Bequer of the Negev Desert in Israel. Anabat detector II was used to detect the activity of bats following both focal and continuous techniques. Horizontal and vertical vegetation covers were estimated at subjective index. Arthropods were counted at four stations within each wadi, temperatures were measured with a thermometer at sampling sites, and cloud cover and wind speed were determined by a subjective index. Even though there is weak relationship between vegetation and bat activity, there seems to be a trend between them. Strong correlation was demonstrated between flying insects and bat activity from the continuous recording $\left(\mathrm{R}^{2}=0.92\right.$, F-test $\left.=22.23, \mathrm{P}=0.042\right)$ confirming our main predictions but no relationship was found between the focal sampling of bat activity and arthropod abundance. Cloud cover and wind speed did not affect the bat activity but temperature was found to reduce the flight of a flying insect and hence the activity of bats. Our experience from this study reflects the efficacy of using continuous acoustic monitoring over the focal sampling in detecting bat activity.
\end{abstract}

\section{Keywords}

Bat activity, acoustic sampling, Negev Desert, Israel

\section{Introduction}

The activity of bats is influenced by a number of factors, often interacting, abiotic and biotic factors. Biotic factors such as quantity and type of food, predation pressure, vegetation cover, and abiotic factors like ambient temperature, light intensity, wind strength and noise are widely reported in having effect on the activity of these unique mammals. If we look at some of the prevailing facts about the relationship between bat activity and these factors from the existing body of literature, it might give us a general picture on the topic. Clutter on water bodies and noise of turbulent waters reduced the foraging efficiency of Myotis lucifugus and preference for calm bodies of water over turbulent ones (von Frenckell \& Barclay, 1987) was observed because the high frequency sound produced by running waters masked the weak echoes and then reduced prey detection efficiency (Mackey \& Barclay, 1989). Rydell et al. (1996) reported the relationship between the activity patterns of flying insects with the activity of bats. According to this study aerial insects, of sizes taken by bats, were more abundant during the day than during the night but the highest abundance usually occurred around dusk partly reflecting increased flight of dipterans. Verable (1943), Church (1957) and Stebbings (1968) on the other hand reported that the time of first emergence of Pipistrellus pipistrellus from the roost is related to the time of sun set. Some species of bats are constrained from exploiting most of the evening peak in aerial insects abundance because their earlier emergence had resulted in higher predation risk by raptorial diurnal birds at higher light levels (Speakman, 1995).

Other studies, however, indicated that bats used sheltered habitats as a means of protection from birds of prey and were found foraging during early evening following high insect activity at dusk (Rydell, 1996). Similarly, Limpens et al. (1989) and de Jong (1994) argued the importance of patches, corridor of trees as a protection means for commuting and foraging bats during the early part of the evening and in the morning. This allowed the bats to emerge earlier and return later thus exploiting more of the dusk and down peaks in the flight activity of insects (Jones etal., 1995).

In arid ecosystems, water is the most limiting factors for the functioning of the biota. Studies conducted in these habitats generally demonstrated relationship between the amounts of water or soil moisture in wadi (the shallow foothills) floors with 
the size of the wadies. The variability of moisture in wadies of different sizes also showed strong correlation with the vegetation density and the diversity of desert community (Shmida, 1990). In this study our main prediction was that if the size of a wadi increases, the associated relative increase in vegetation cover would create diverse microhabitats leading to increased arthropod diversity and consequently to increased bat activity. Wadies that are relatively small on the contrary, should therefore have relatively low bat activity. Our second prediction is that, there is no significant difference between continuous and focal acoustic sampling methods in recording the activity of bats. In addition, during sampling, we recorded the abiotic factors such as wind strength, cloud cover and ambient temperatures to test if there is any relationship between these factors and bat activity.

\section{Materials and Methods}

The study was carried out in four different locations (wadi, the shallow foot hills), namely, the Lost wadi, Tree wadi, Hill wadi and the Zin wadi around Sede Boqer, Negev. Each wadi was unique for its vegetation cover and water availability.

The subjective index (SI) was followed to measure the vegetation density across a transect of $1000 \mathrm{~m}$ divided into six stations. Both horizontal and vertical observations at each station was taken at an interval of $2 \mathrm{~m}, 4 \mathrm{~m}, 6 \mathrm{~m}, 8 \mathrm{~m}$, and $10 \mathrm{~m}$ with horizontal width of $2 \mathrm{~m}$ both on right and left side of the observation points. Bat echolocation calls consist of repetitive patterns commonly referred to as pulses (Aldridge \& Rautenbach, 1987), calls (Neuweiler, 1984; Jones, 1994) or sequences. The bat activity (measured by the number of sequences) was monitored using focal sampling and continuous sampling (Altman, 1974) in the four distinct locations (wadies) in the Negev Desert during the night. The sequences were recorded using Anabat II detector following Hayes and Hounihan (1994). Echolocation calls were recorded on audiotape as bats flew over or near the monitoring station. The calls recorded were further analyzed.

The population of insects was recorded following the focal sampling of bat call at each station in a 20-meter transect using a spotlight $(\mathrm{V})$. Both terrestrial and flying insects were recorded separately. Search at each station lasted for seven minutes. Temperature, wind strength and cloud cover were also recorded as part of abiotic observation. Cloud cover and wind strength were rated subjectively ranging from 0 being the lowest and 4 being the highest on a range of 0 to 4 .

Totally, 30 observations from each location / wadi were taken during the study period.

\section{Results}

The results from the observations were classified into three categories: a) biotic factors and bat activity; b) abiotic factors and bat activity; and c) evaluation of focal and continuous sampling techniques.

\section{Biotic factors and bat activity}

i. Bat activity and vegetation density

The Lost and Tree wadies had low horizontal vegetation density compared to the Hill and the Zin wadies. The continuous acoustic sampling showed weak relation $\left(R^{2}=0.34, F=1.05\right.$ and $\mathrm{P}>0.5$ ) between the vegetation cover and bat activity. The focal sampling, however, did not reflect any relationship neither with the horizontal nor with the vertical vegetation (Fig. 1). Bat sequences were recorded higher at Hill wadi.

ii. Insect density and bat activity

The number of bat sequences from focal acoustic monitoring did not show differences across all sampling sites with respect to number of available insects. The continuous sampling, however, showed an increasing trend in site 1, 2 and 4 following the same trend of the available flying insects $\left(\mathrm{R}^{2}=0.98, \mathrm{~F}=22.23\right.$ and $\mathrm{P}<0.042$, Fig. 2). A sharp decline of bat activity from the continuous method was observed in the third site. Bat activity and insect availability showed a positive trend but not significant. We could not find any trend between insect density and bat activity through focal sampling method.

iii. Vegetation density and insect density

The vertical and horizontal vegetation did not differ significantly across the transects. The number of terrestrial insects was more in the sites with higher vegetation, however, not very significant $\left(\mathrm{R}^{2}=0.52, \mathrm{~F}=2.21, \mathrm{P}=0.28\right)$ for vertical vegetation and $\left(\mathrm{R}^{2}=\right.$ 0.03 , F-test $=0.07, \mathrm{P}=0.82$ ) for horizontal vegetation. Flying insects showed a trend with the vegetation cover of the wadies but no relationship was found $\left(\mathrm{R}^{2}=0.003, \mathrm{~F}=0.006, \mathrm{P}=0.95\right)$ for vertical vegetation and $\left(\mathrm{R}^{2}=0.1,0.25, \mathrm{P}=0.67\right)$ for horizontal vegetation (Fig. 3).

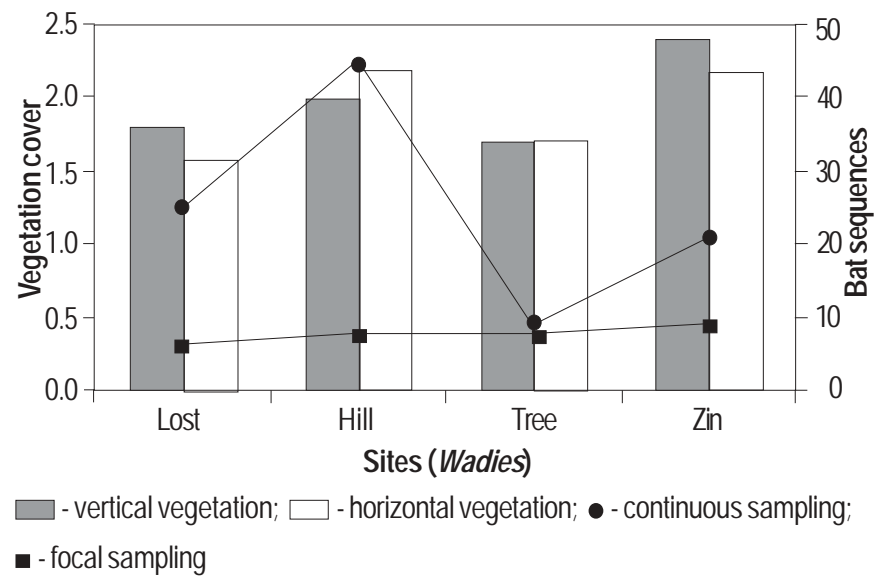

Figure 1. Bat activity and vegetation cover 


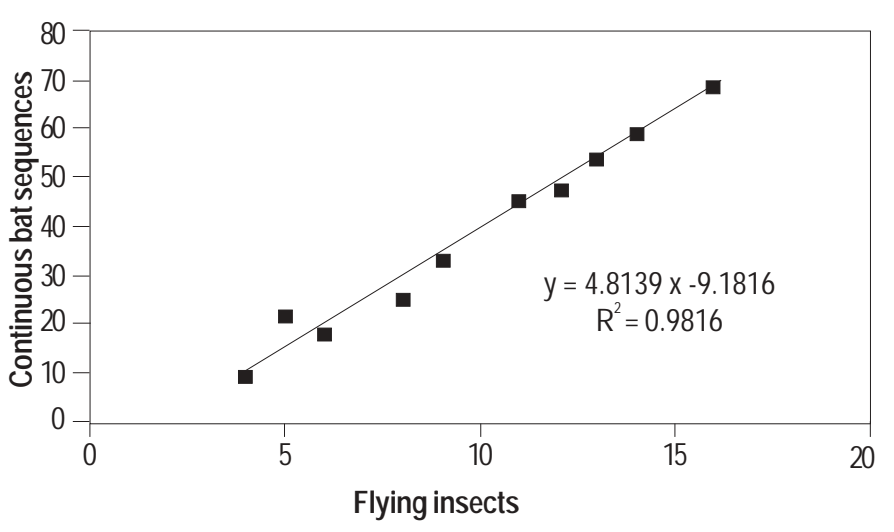

Figure 2. Correlation between continuous bat sequences and flying insects

\begin{abstract}
Abiotic factors and bat activity
All environmental factors considered in the study like cloud cover, temperature, and wind strength did not show a conspicuous effect on the activity of bats in either of the methods. The wind speed was very high in Hill and Tree wadies, but it was moderate in the rest. The temperatures varied from $20^{\circ} \mathrm{C}$ in the Lost wadi to $16^{\circ} \mathrm{C}$ in the Zin wadi. Cloud cover was observed only on one day of the observation in the Lost wadi (Table 1).
\end{abstract}

Evaluation of focal and continuous acoustic sampling methods From the paired t-test analysis, significant differences were obtained between focal and continuous acoustic sampling methods $(\mathrm{P}>0.05)$. In all the continuous acoustic monitoring method, more number of bat sequences in all sites except in the Tree Wadi were recorded compared to the focal sampling method.

\section{Discussion}

Studies made in the Negev Desert repeatedly indicated strong correlation between the amount of moisture in the wadies and the size of the wadies. The vegetation cover in wadi crust much reflected the amount of moisture contained in the riverbed and this in turn indicated the relative quality of the wadies. Similarly, in this study a positive trend was observed between the

Table 1. Abiotic factors influencing bat activity

\begin{tabular}{llllll}
\hline Sites & \multicolumn{2}{l}{ Temperature Cloud } & Wind & \multicolumn{2}{c}{ Bat activity } \\
& $\left({ }^{\circ} \mathrm{C}\right)$ & cover & strength & Focal & Continuous \\
\hline Lost Wadi & 20 & 3 & 4 & 7 & 25 \\
Hill Wadi & 17 & 0 & 4 & 8 & 45 \\
Tree Wadi & 16 & 0 & 4 & 8 & 9 \\
Zin Wadi & 16 & 0 & 3 & 10 & 21 \\
\hline
\end{tabular}

(all the values are average of 30 observation)

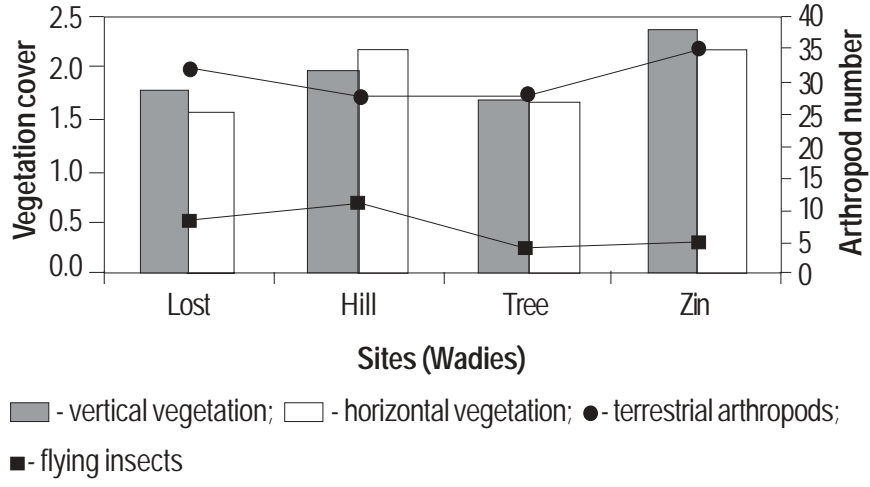

Figure 3. Vegetation cover and insect number in the four Wadies

vegetation cover of the quality of the wadies in attracting insects and in turn the bats. The vegetation overall showed increasing trend in cover as we moved from the smallest (Lost) to the largest (Zin) wadi. The slight decrease observed in the third (Tree) wadi might be attributed to the difference normally encountered in vegetation cover within a wadi due to slight topographic differences within the habitat.

Diversity of microhabitats as a result of more vegetation cover enhances the diversity of other organisms in a habitat. This trend is also witnessed in arthropod diversity in the Negev Desert (Brandt \& Lubin, 1998). From our observations also arthropods generally indicated an increasing trend in numbers, which is probably linked to arthropod diversity with increased habitat diversity.

The low number of aerial insects in the night, in contrast to the high number in the day time, compared to the terrestrial ones was probably related to low temperatures and high wind recorded at the sampling time, which usually decreases flying insect activity (Taylor, 1986; McGeachie, 1989). Many studies (Swift, 1980; Rydell et al., 1996) have confirmed the positive association between the activity of flying insects and the activity of bats. According to Rydell et al. (1996), aerial insects of the sizes taken by bats were more abundant during daytime than during the night and the activity pattern of night flying insects correspond with the activity of bats. But it could also be possible that activity peak of flying insects in the wadies throughout the night may change and hence bats follow those bi- or multimodal insect activity peaks (Erkert, 1982; Rydell et al., 1996). Since we did not perform time series bat calls sampling throughout the night, we are not very certain about the phenomenon. In this study, bat activity from the continuous sampling method has reflected a significant relationship with flying arthropods. However, correlation was not found between the terrestrial insect and either of the acoustic sampling methods 
though the number of terrestrial arthropods (insects and scorpions) was uniformly greater than flying insects across all the wadies.

When we try to look for direct relationship, not through the functional role of vegetation in increasing the abundance and diversity of arthropods, but between vegetation cover and bat activity, different arguments are encountered in documented literature. According to Rydell et al. (1996) and Speakman (1995), protective tree cover might have allowed early evening emergences of bats, therefore providing access to more food at dusk. Similarly, Speakman (1995) associated the timing of bats foraging flight with the light conditions at the time of emergence from roosts indicating predation risk as the most likely factor for this effect. Presumably, the risk of being caught by a visually oriented predator decreases with decreased light level, and trees and shrub patches proved protection for commuting and foraging bats during dusk and dawn (Limpens et al., 1989). But no significant predation pressure on insectivore bats has been recorded in the studied habitats.

Therefore, the weak relationship observed between bat activity from the continuous method and proportionately increasing vegetation cover with increasing wadi size is most likely related from functional role of the vegetation in creating diverse microhabitats for the relatively diverse biotic communities including arthropods. Since our sample size is limited $(n=30$, at each location) we lack the statistical backing to rely on the statement of the results. However, the indications from this small sample size are important for further probe and we recommend further study on the issues with enough sample sizes and time series observations in relation to different bat species.

Apart from the declining temperatures excepting in the first wadi, no relationship between the cloud cover and wind strength was found to effect bat activity. Our results in this regard substantiate the results of the studies of Mills (1986), and Leonhard and Fenton (1983).

In this study the continuous acoustic sampling method had resulted more bat sequences than the focal method. The calls from the continuous sampling method showed a better correlation with insects and showed the weak trend with vegetation cover. The focal method on the contrary did not produce sufficient sequences to monitor bat activities and no trend was established with the vegetation cover and insect number.

The relative efficacy of the continuous method in recording sufficient and actual representative bat sequence as a measure of bat activity is apparently related to two factors. First, in continuous recording bat calls are recorded across the whole range of the sampling area and thus gives a wider range to record sufficient bat activity. Second, during the slow continuous walk across the sampling distances during continuous method, the chance that the same bat would be recorded more than once thus increasing the number of sequences recorded during the stipulated seven minutes at each station along the sampling area. Therefore, we recommend that continuous sampling method gives better results than the focal method in studying the activity of bats vis-à-vis biotic and abiotic factors.

\section{Conclusion}

The activity of bats in different sized wadies of Negev indicated "weak relationship" with the vegetation cover but strong correlation with flying insect activity. Temperature indirectly affected bat activity by reducing the flight of flying insects in the night but no relationship was found between cloud cover and the wind strength. The continuous sampling method was found much better than the focal method in recording enough bat calls as a measure of bat activity and depicting the link between abiotic and biotic factors.

\section{Acknowledgement}

We would like to express our sincere thanks and appreciation to the Director, The $4^{\text {th }}$ International MASHAV course on Conservation of Biodiversity in Desert Ecosystem, Dr. Boris Krashnov, for his kind and unreserved advise, support, encouragement and guidance from the start through to the completion of the project. Our gratitude also goes to the cocoordinators of this program, the lecturers and finally to the ministry of foreign affairs, Israel, for giving us this opportunity and financial help. We are also thankful to Mr. C.K. Borad for his comments on the first draft of the manuscript.

\section{References}

Aldridge, H.D.J.N. and I.L. Rautenbach (1987). Morphology, echolocation and resource partitioning in insectivorous bats. Journal of Animal Ecology 56: 763-778.

Altman (1974). Animal Behaviour 70: 9-21.

Brandt, Y. and Y. Lubin (1998). An experimental manipulations of vegetation structure: consequences for desert spiders. Israel Journal of Zoology 44:201-216.

Church, H.F. (1957). Times of emergence of the Pipistrelle. Proceedings of the Zoological Society of London 128: 600-602.

de Jong, J. (1994). Distribution patterns and habitat use by bats in relation to landscape. Wildlife Ecology 26: 1-130.

Erkert, H.G. (1982). Ecological Aspects of Bat Activity Rhythms. Plenum Press pp. 201-242.

Hayes, J.P. and P. Hounihan (1994). Field use of Anabat II detector system to monitor bat activity. Bat Research News 35: 1-3.

Jones, G. (1994). Scaling of wing bat and echolocation pulse emission rates in bats: why are aerial insectivorous bats so small? Functional Ecology 8: 450-457.

Jones, G., R.D. Ransom and P.L. Duverg (1995). Conservation Biology of Endangered Species: Field Studies of Greater Horse-shoe Bats, 
pp.309-324. Oxford.

Leonhard, M.L. and M.B. Fenton (1983). Habitat use by spotted bats (Euderma maculatum): roosting and foraging behaviour. Canadian Journal of Zoology 61: 1487-1491.

Limpens, H.J.G., W. Helmer, A. Winden and K. Mostert (1989). Bats and linear landscape. Lutra 32: 1-20.

Mackey, R.I. and M.R. Barclay (1989). Influence of physical clutter on activity of bat over water. Canadian Journal of Zoology 67: 11671170

McGeachie, W.J. (1989). Effect of moonlight illuminance, temperature and wind speed on light trap catches of moth. Bulletin of Entomological Research 79: 185-192.

Mills, A.M. (1986). The influence of moonlight on the behaviour of goatsuckers. Auk 103: 370-378.

Neuweiler, G. (1984). Foraging, echolocation and audition in bats, Naturwissenschaften 71: 446-455.

Rydell, J., A. Entwistle and P.A. Racey (1996). Timing of foraging flights of three species of bats in relation to insect activity and predation risk. Oikos 76: 243-252.

Shmida, A. (1990). Handbook of Wild Flowers of Israel Desert Flora. Ketter Publishing House Ltd.

Speakman, J.R. (1995). Chiropteran Nocturnality, pp. 187-201. Oxford.

Stebbings, R.E. (1968). Measurement, composition and behaviour of large colonial bats. Journal of Zoology 156: 15-33.

Swift, M.S. (1980). Activity patterns of Pipistrelle bats (Pipstrellus pipstrellus) in Northeast Scotland. Journal of Zoology 190: 285-295.

Taylor, L.R. (1986). Time series analysis of number of Lepidoptera caught at light traps in East Africa and the effects of moonlight on trapped efficiency. Bulletin of Entomological Research 76: 593-606.

Verable, L.S.V. (1943). Observation at Pipistrelle bat roost. Journal of Animal Ecology 12: 19-26.

von Frenckell, B., and R.M.R. Barclay (1987). Bat activity over calm and turbulent water. Canadian Journal of Zoology 65: 219-222.

\section{CATTLE EGRET (BUBULCUS IBIS) ATTEMPTING TO FEED ON BROWN ROCK CHAT (CERCOMELA FUSCA) CHICK}

\author{
R.M. Kasambe
}

Wildlife and Environment Conservation Society, M.R. Colony MIDC Bypass, Amravati 444606, India.

On 17 May 2001 at $0545 \mathrm{hr}$ when I was watching birds, I found four Brown Rock Chats (Cercomela fusca Blyth ) making loud noises and hovering over a Cattle Egret (Bubulcus ibis). The latter was holding a small bird alive in its beak and striking it on the ground. When I approached the bird it dropped the prey and flew away. The prey was a chick of Brown Rock Chat and soon the chick died from serious injuries near its neck, both shoulders and thighs. I left the dead chick and retreated to observe the behaviour of the four Brown Rock Chats until 0645hr. The four birds hovered restlessly and noisily over the dead chick. These birds had not attacked the predator when the Cattle Egret was holding the chick in its beak.

One Brown Rock Chat sat on a soil mound, the other two birds sat at some distance at a construction site and the fourth one first flew over the dead chick, tried to keep flying over it for few seconds uttering short harsh calls. Then it sat very close to the dead chick (on one foot) with opened wings and fluttered vigorously. It bent forward with lifted tail and gave harsh calls to the chick. Again it flew over the chick for few seconds and repeated the same behaviour described above for half an hour. After every few displays the bird sat on the soil mound or at the construction site while another bird took over. This way each bird took turns to guard the dead chick.

At $0645 \mathrm{hr}$, even though ants had started eating the dead chick, the four birds were still trying to guard the dead chick. 